Abstracta Iranica Abstracta Iranica

Revue bibliographique pour le domaine irano-aryen

Volume 26 | 2005

Comptes rendus des publications de 2003

\title{
Il Cinema persiano. 2003, Roma, Jouvence, 288 p., notes, biblio., indexes, phot. coul.
}

\section{Poupak Rafii Nejad}

\section{(2) OpenEdition \\ 12 Journals}

Édition électronique

URL : http://journals.openedition.org/abstractairanica/832

ISSN : 1961-960X

\section{Éditeur :}

CNRS (UMR 7528 Mondes iraniens et indiens), Éditions de l'IFRI

\section{Édition imprimée}

Date de publication : 15 mai 2005

ISSN : 0240-8910

\section{Référence électronique}

Poupak Rafii Nejad, « I/ Cinema persiano. 2003, Roma, Jouvence, 288 p., notes, biblio., indexes, phot. coul. », Abstracta Iranica [En ligne], Volume 26 | 2005, document 490, mis en ligne le 18 novembre 2005, consulté le 25 septembre 2020. URL : http://journals.openedition.org/abstractairanica/832

Ce document a été généré automatiquement le 25 septembre 2020

Tous droits réservés 


\title{
Il Cinema persiano. 2003, Roma, Jouvence, 288 p., notes, biblio., indexes, phot. coul.
}

\author{
Poupak Rafii Nejad
}

1 Un copieux ouvrage sur le cinéma iranien depuis sa création. Il est composé de trois chapitres, une bibliographie, un index des réalisateurs, un index des films, et 53 illustrations (plans de films, photos de quelques réalisateurs et reproduction de quelques affiches de film). Tout en respectant l'ordre chronologique des événements et la coupure historique (avant et après la révolution), les deux premiers chapitres vont au-delà de la chronologie et l'histoire par l'excellente analyse de l'auteur. L'évolution du cinéma iranien est souvent mise en parallèle avec celles du cinéma européen et du cinéma hollywoodien. En fait, le passage du muet au sonore, le cinéma progressiste et « la nouvelle vague » iranienne suivent plus ou moins le cinéma mondial alors que les années de silence (1937-47) en Iran correspondent aux années de grande expansion du cinéma européen et hollywoodien. «La naissance de la critique»; "Les revues cinématographiques »; «Le festival de film »; «Les années de crise » sont les parties importantes du premier chapitre.

2 Considéré comme un des facteurs de l'occidentalisation du pays, le cinéma postrévolutionnaire passe selon l'A. d'abord par une période de déclin pour arriver à une période de transition qui donnera naissance à un cinéma islamique. Le tournant dans le cinéma post-révolutionnaire se situe entre 1983 et 1990 avec la productions de 450 films parmi lesquels de nombreux ont reçu des prix et des distinctions sur les scènes internationales. Depuis les années 90, l'A. observe une mutation confirmée par de nombreux exemples de films et les réactions que ces films ont pu susciter à différents niveaux nationaux ou internationaux.

3 Le troisième chapitre ouvre une nouvelle dimension sur le cinéma iranien. L'A. présente ici les thèmes spécifiques abordés dans les films. Les films pour les enfants, le rapport étroit entre le cinéma et la littérature et leurs influences réciproques ainsi que 
le cinéma au féminin et la présence des femmes dans le cinéma iranien sont les sujets remarquablement développés dans ce dernier chapitre.

INDEX

Mots-clés : Cinéma iranien, histoire du cinéma iranien

Keywords : Iranian cinema, history of the Iranian cinema

Thèmes: 17.2. Arts du spectacle

\section{AUTEURS}

POUPAK RAFII NEJAD

CNRS - Paris 